Recibido: 22/03/2016

Aprobado versión definitiva: 31/04/2016

\title{
SITUACIONES DE VIOLENCIA EXPERIMENTADAS POR DOCENTES DE ESCUELAS PRIVADAS DE MINAS GERAIS: ANÁLISIS EXPLORATORIO DE UN TEMA RECURRENTE
}

\author{
CLÁUDIA CRISTINA RIOS CAXIAS DA COSTA ${ }^{1} /$ ALEXANDRE MAGNO ALVES \\ DINIZ² / RENATO MOREIRA HADAD ${ }^{3}$ / SANDRA PEREIRA TOSTA ${ }^{4}$
}

\section{RESUMEN}

Generalmente, los docentes presencian eventos considerados violentos en su ambiente de trabajo. El presente estudio, de naturaleza exploratorio, utiliza datos provenientes de la investigación: "Rede particular de ensino: vida de professor e violência na escola", dirigida por Sinpro Minas, en conjunto con los Programas de Postgrado en Educación y Geografía-Tratamento de la Información Espacial de la PUC Minas. A través del cuestionario diseñado, se busco verificar, la percepción de 686 docentes sobre la violencia en los estabelecimentos educativos del sector privado en Minas Gerais, en el año 2008, priorizando los actores involucrados en las modalidades de violencia sistemática, observadas con mayor frecuencia. Se concluye que las aulas son u espacio de tensión entre el professor y el alumno, y es permanente que el docente experimente situaciones de violencia.

Palabras clave: Docentes, Escuelas privadas, violencia, Brasil, Minas Gerais, SINPRO Minas

\footnotetext{
${ }^{1}$ Doutora em Geografia de Pontifícia Universidade Católica de Minas Gerais. Afiliada a la Pontifícia Universidade Católica de Minas Gerais. Rua Dom José Gaspar, 500 - Coração Eucarístico, Belo Horizonte - MG, 30535-901, Brasil. Correo electrónico: riosdacosta@gmail.com

2 Doutor em Geografia de la Arizona State University (USA). Afiliado a la Pontifícia Universidade Católica de Minas Gerais. Rua Dom José Gaspar, 500 - Coração Eucarístico, Belo Horizonte - MG, 30535-901, Brasil. Correo electrónico: alexandremadiniz@gmail.com

${ }^{3}$ Doutor em Ciência da Computação de la Universidad Federal de Minas Gerais. Afiliado a la Pontifícia Universidade Católica de Minas Gerais. Rua Dom José Gaspar, 500 - Coração Eucarístico, Belo Horizonte - MG, 30535-901, Brasil. Correo electrónico: renatohadad@oi.com.br

4 Doutora em Antropologia Social de la Universidad de São Paulo. Afiliada a la Pontifícia Universidade Católica de Minas Gerais. Rua Dom José Gaspar, 500 - Coração Eucarístico, Belo Horizonte - MG, 30535-901, Brasil. Correo electrónico: sandrapereiratosta@gmail.com
} 


\section{SITUATIONS OF VIOLENCE INVOLVING TEACHERS IN PRIVATE SCHOOLS IN THE STATE OF MINAS GERAIS: EXPLORATORY ANALYSIS ABOUT A RECURRING THEME}

\section{ABSTRACT}

Generally speaking, pedagogues have witnessed events considered violent in their work environments. This exploratory study used data from the research " Private Sector Schools: pedagogue's life and violence in school " facilitated by Sinpro Minas, in partnership with the PUC Minas Postgraduate Programs in Education and in Geography - Spatial Information Treatment. Using a structured questionnaire, which sought to verify the perception of 686 pedagogues on violence in private sector schools in Minas Gerais, in 2008, highlighting the actors involved in variants of continuous violence that have been observed more frequently. We concluded that the classroom environment has been the scene of tension between teacher and student, and the involvement of pedagogues in violent occurrences has been continuous.

Keywords: Pedagogue, Private Sector Schools, Violence, Brazil, Minas Gerais, SINPRO Minas.

\section{SITUAÇÕES DE VIOLÊNCIA ENVOLVENDO O DOCENTE NAS ESCOLAS PARTICULARES MINEIRAS: ANÁLISE EXPLORATÓRIA SOBRE UM TEMA RECORRENTE}

\section{RESUMO}

De forma generalizada, docentes presenciam eventos considerados violentos em seus ambientes de trabalho. O presente estudo, de cunho exploratório, utilizou dados provenientes da pesquisa "Rede particular de ensino: vida de professor e violência na escola", capitaneada pelo Sinpro Minas, em parceria com os Programas de Pós-graduação em Educação e GeografiaTratamento da Informação Espacial da PUC Minas. Através de questionário estruturado, buscou-se verificar, a percepção de 686 docentes sobre a violência nos estabelecimentos de ensino do setor privado em Minas Gerais, no ano de 2008, priorizando os atores envolvidos nas modalidades de violência continuada, 
observadas com maior frequência. Conclui-se que a sala de aula é o palco de tensão entre professor e aluno e é contínuo, o envolvimento docente nas situações de violência.

Palavras chave: Docentes, Escolas particulares, Violência, Brasil, Minas Gerais, SINPRO Minas.

\section{Introdução}

Agressividade e violência são termos que acompanham a história da humanidade desde os seus primórdios. Enredos e perfis violentos clássicos encontram-se na Bíblia e na filosofia, a exemplo do célebre Livro IX da República de Platão (1990). Nele o filósofo retrata, detalhadamente, o homem tirânico, o mais violento dos homens, já que é hospedeiro de todos os vícios.

Conforme Lorenz (citado por Fromm, 1982); "todos os seres humanos, assim como os animais trazem consigo um impulso agressivo e nato necessário à sobrevivência da espécie". Partindo desse pressuposto, a agressividade pode ser considerada uma manifestação natural, bem como um componente emocional que faz parte, necessariamente da afetividade dos indivíduos. Por ser compreendida como um problema grave, pois fere a integridade física e psicológica dos indivíduos, a violência é tema constante de investigações e indagações (Fromm, 1982).

No ambiente familiar e escolar, é notório o avanço dos atos violentos, sobremaneira neste último, concebido como local dedicado à reflexão e ao conhecimento. A violência praticada no cotidiano escolar pode assumir muitas formas, mas na prática do bullying, comumente verifica-se o exercício da violência simbólica. Essa terminologia é definida por Zaluar e Leal (2001, p.148) como "a violência que se exerce também pelo poder das palavras que negam, oprimem ou destroem psicologicamente o outro". Essa prática, na maioria das vezes é contínua, persistente e não precisa de razões para acontecer.

A violência proveniente de fatores sociais, psicológicos e pedagógicos demonstra o desafio da socialização e do respeito comum que têm faltado nos ambientes escolares. Sabe-se que atualmente, a escola é exigida a repassar conteúdos, muitas vezes a substituir a conduta que deveria ser ensinada pelos 
pais e, sobretudo, é impulsionada a repetir conhecimento e formar mão-de-obra ao mercado, sem que haja uma profunda preocupação com a formação de cidadão.

Há algum tempo, a lousa, o caderno, o lápis e a borracha, tão comuns à sala de aula, convivem com o porte de armas, a atuação de gangues, o tráfico de drogas, o furto e a agressão física e verbal. Não raro a "lei do silêncio" predomina entre profissionais que trabalham em escolas, principalmente naquelas alocadas em áreas tidas como de "risco social".

O aumento dos índices de violência contra discentes e docentes no ambiente escolar vem municiando os noticiários de maneira aterradora, onde a abordagem da temática polissêmica e controversa, que sempre existiu, se apresenta sob a forma de violência continuada ${ }^{5}$. Esta modalidade de agressão contra o docente resulta em comprometimento da sua saúde emocional, da qualidade das relações humanas, prejuízo da construção da cidadania e do processo educacional.

Dados da Unesco (citado por Abramovay, 2006), revelam que $80 \%$ dos docentes das principais capitais brasileiras enfrentaram, em algum momento, violência no trabalho. Em Minas Gerais, um levantamento feito em 2010 pelo Sindicato dos Professores do Estado de Minas Gerais (SINPRO-MG), revelou que a cada três dias, um caso de violência é registrado contra docentes em escolas públicas ou privadas do estado. Baseado em dados oriundos desta agremiação docente, datados de 2008 , bem como no aporte teórico-metodológico correlato ao tema, este estudo de cunho exploratório pretende evidenciar o panorama da violência contra o docente da rede particular de ensino no Estado, priorizando os atores envolvidos nas modalidades de violência continuada observadas com maior frequência, buscando assim, entender a dificuldade que os professores enfrentam para desempenhar as suas atividades laborais.

\footnotetext{
${ }^{5} \mathrm{Na}$ literatura internacional, mais conhecida como bullying.
} 
Por ser comum nas instituições de ensino brasileiras que seus responsáveis neguem ou atenuem a existência de violência no seu interior, principalmente para preservar a imagem dos estabelecimentos e a sobrevivência destes ante a incapacidade de tratar dos transtornos diários, é que se justifica esta pesquisa.

\section{A violência no âmbito escolar: pressupostos}

A história da humanidade testemunha que a violência sempre esteve presente na vida do homem, quer seja pela sede de poder, pelas disputas afetivas ou mesmo pelo desejo de conquistar espaços, em menor ou maior escala. Até mesmo, no que se denomina processo civilizatório, a violência é justificada por falsas verdades que acabam por sucumbir os mais fracos. De acordo com Tosta et al (2009), a sociedade convive com a violência diária e somente se apercebe dela quando detectada algum tipo de ameaça e desrespeito à vida: o trânsito violento, as drogas, a miséria material, o abandono social e a desesperança, assim como o descompromisso político.

Atentar somente para o produto da violência, sem, no entanto olhar sua gênese e os processos que a mantém, tende a dividir o mundo entre vítimas e vitimizadores. Os menos atingidos pelos mecanismos de exclusão social se defendem dos mais atingidos e estes, em resposta, tendem a revidar. Assim, instalam-se o caos, a desconfiança e o medo.

Olweus (1993) foi um dos primeiros a realizar estudos sobre violência no ambiente escolar. Ele desenvolveu os primeiros critérios ${ }^{6}$ para a identificação do bullying na escola, diferenciando-o de outras possíveis interpretações sobre o comportamento dos estudantes.

Sposito (2001), em artigo onde se verifica um balanço das pesquisas sobre violência escolar no Brasil, destaca que a relação conflituosa entre alunos e

\footnotetext{
${ }^{6}$ O questionário desenvolvido por Olweus denominado "Olweus Bully/Victim Questionnaire", cuja primeira versão data de 1983, é certamente o instrumento mais difundido nas pesquisas sobre o fenômeno de violência continuada. O mesmo é constituído por 25 questões de múltipla escolha, relacionadas às características sociodemográficas, relações de amizade e as principais características de vitimização e agressão verificadas no ambiente escolar.
} 
professores tem gerado um medo constante entre os docentes, que frequentemente apelam para a segurança policial. Este procedimento afeta a qualidade da interação educativa e o clima escolar, evidenciando a desconstituição da autoridade como um dos principais constrangimentos presentes no cotidiano docente.

Charlot (2002) caracteriza a violência escolar, subdividindo-a em: violência na escola, violência à escola e violência da escola. O autor argumenta que esta distinção é importante no sentido de que se a escola é, em grande medida, impotente com respeito à violência no seu interior, isto é, a violência que é reflexo do mundo externo, ela não o é com respeito a sua ação face à violência da escola e à escola. Abramovay (2004), mediante pesquisas sobre violência escolar, realizadas na América Latina e Caribe, concebe a violência, como a intervenção física de uma pessoa ou grupo, contra a integridade de outras pessoas ou de grupos e contra si mesma.

Hanke (1996), Ortega (2001), Blaya (2002) e Marra (2007) também discutem a violência escolar e as várias implicações econômicas, sociais e culturais que devem ser levadas em consideração ante a sua abordagem. Todavia, entre eles há certo consenso de que não só a violência física merece atenção, já que outros tipos podem ser tão graves quanto esse, a exemplo da xenofobia e do bullying.

Buscando investigar a relação entre alunos, Camacho (2001), constata que as agressões entre pares são cometidas principalmente nos intervalos entre as aulas, nos pátios, no recreio e nos corredores. Na sala de aula sua incidência é menor embora esteja presente de modo disfarçado, quase sempre envolvendo brincadeiras. Isto sugere uma relação entre o aumento de maus tratos e agressões a uma maior possibilidade de impunidade, pela não presença de professores.

Verificou-se também, que os estudos sobre a violência escolar têm apontado como causas desse fenômeno, a desestruturação familiar e as carências socioeconômicas, aliadas ao tráfico de drogas, sobretudo na rede pública de 
ensino. Entretanto, basta que se atente aos destaques da mídia, para se constatar que, também nas escolas da rede particular de ensino, os episódios de violência têm se feito notar, apesar dos esforços dos donos em sonegar da mídia e da população as informações que poderiam incorrer em grandes perdas financeiras para as instituições.

Na rede particular, as causas da violência também são coincidentes com as causas encontradas na rede pública, excetuando-se as carências socioeconômicas. Desta forma, cai-se o mito de que a pobreza induz à violência. Na verdade, a pobreza é uma violência, mas, não é a causa direta da violência, pois as variáveis geradas pela condição de pobreza podem estimular os atos violentos, mas a pobreza por si só não produz a violência (Espinheira, 2004).

\subsection{0 bullying entendido neste estudo como crime}

Sendo o crime um fenômeno social e episódio, na vida de um individuo, considerar-se-á o bullying como um evento que se enquadra nesta definição, ainda que, juridicamente não o seja. De acordo com Olweus (1993), o bullying é definido como um subtipo de comportamento agressivo que gera atos violentos e, na maioria das vezes, ocorre dentro das escolas. Cenas de violência e hostilidade permeiam ambientes escolares a todo instante, mas, na maioria das vezes, essa violência é vista de forma lúdica. Os atos violentos, que não estão restritos a nenhum tipo de instituição escolar, estimulam a delinquência e induzem a outras formas de comportamento com desvios de conduta.

Segundo Fante $(2005$, p.27), a palavra bullying é um “(...) termo que conceitua os comportamentos agressivos e anti-sociais, utilizado pela literatura psicológica anglo-saxônica, nos estudos sobre o problema da violência escolar". Adotado por um ou mais alunos contra outro(s), ou destes contra ou na presença do docente, causando dor, angústia e sofrimento. Sendo a violência oculta a principal característica da prática do bullying. Comentários maldosos, apelidos depreciativos, fofocas ou deboches que ocorrem sem motivação evidente tornando possível a intimidação da vítima, são exemplos comuns deste fenômeno. 
Assim, o bullying não se expressa somente através de murros e tapas, mais também, por meio de zombaria e do ridículo contra a integridade moral do individuo alvo de chacotas. Apelidados e excluídos do meio social, seja por suas atitudes, maneira de se vestir ou de pensar, as vítimas deste comportamento violento tomam pavor do ambiente escolar resultando, não raro, na evasão e abandono do mesmo.

As situações de bullying não provocam evasão escolar de imediato, visto que essas situações são suportadas pelas vítimas de bullying que tentam conviver com as ocorrências ao longo do tempo. Em alguns casos, ocorre a transferência de escola, mas não o abandono. (Jacometti et al., 2014)

O bullying no ambiente escolar tornou-se uma prática cada vez mais comum, não poupando discentes e docentes que enfrentam esse tipo de violência, diariamente. A luz dos fundamentos da Geografia do Crime, este estudo objetiva analisar este comportamento, sob a ótica dos docentes mineiros lotados em instituições particulares, como meio de se reafirmar ou de se impor diante das regras da instituição e das pessoas com as quais convive. A literatura disponível, ainda incipiente sobre o tema, abarca que os educadores têm interesse em reduzir esses comportamentos, pois acreditam que os mesmos prejudicam o seu trabalho em sala de aula.

Para Candau (2002, p.142), os docentes não conseguem resolver sozinhos, esse problema tão complexo, pois têm dificuldade em identificar as formas de violência presentes no ambiente escolar e muitas vezes não se dão conta de que também, estão envolvidos na situação. Assim, a autora ainda afirma que o trabalho docente implica também uma prática social, daí a necessidade de preocupação com a realidade discente e sua formação, almejando-se reflexões ante a prática da violência, bem como as formas de enfrentamento da mesma.

Lopes Neto (2005) coloca a questão da inexistência de políticas públicas que priorizem ações de prevenção ao bullying e garantam a saúde e a qualidade da educação no Brasil. De acordo com o autor, as escolas nem sempre dispõem 
dos meios necessários para prevenir a violência; assim, o trabalho do psicólogo no ambiente escolar tem-se mostrado cada vez mais imprescindível.

A escola deveria proteger as vítimas de bullying, permitindo que estes desenvolvam sua capacidade de autodefesa. Com relação aos agressores, estes necessitam de um ambiente que os eduque para a reflexão de suas ações violentas, bem como ao aprendizado das regras básicas de boa convivência. Nessa perspectiva, os educadores têm que assumir o papel de construtores de contextos significativos, como afirma Constantini (2004):

Crescer próximo ao adolescente significa descobrir, com respeito recíproco e na relação cotidiana, um novo rumo comum, ligado àquilo que acontece na realidade, aos fatos e aos comportamentos concretos, à originalidade de cada um, à troca e ao confronto relacional que pode até ser intenso e conflitual, mas também igualmente importante para aprender a conhecer-se. (p.80)

A escola não deve ser apenas um local de ensino formal, mas também, de formação cidadã, de direitos e deveres, amizade, cooperação e solidariedade. (Fante, 2005, p. 91) "Agir contra o bullying é uma forma barata e eficiente de diminuir a violência entre estudantes e na sociedade".

Algumas atitudes docentes podem colaborar para a implantação de programas de combate ao bullying. Os educadores, por exemplo, não devem criticar publicamente os alunos que costumam tirar as notas mais baixas ou àqueles que são psicologicamente mais frágeis, pois essas atitudes tendem a gerar manifestações de escárnio e chacota. Ao sentirem que podem contar com o apoio dos educadores e demais envolvidos no processo educativo, as vítimas e testemunhas de bullying sentir-se-ão beneficiadas.

\subsubsection{As modalidades de bullying}

Cruz e Pereira (2013) atestam que a violência se apresenta desde a forma mais sutil até as mais perceptíveis e que, embora esse evento esteja presente nos processos pedagógicos, esta não é totalmente percebida, provavelmente pela reprodução da ordem simbólica, socialmente construída e internalizada por docentes e discentes. Quem vivencia a violência, muitas vezes, só pode achar natural o uso da força física. A constatação da impotência da vítima que não 
consegue ver o agressor punido gera a consciência de que, a violência é um fato normal da vida e um meio eficaz de solução de conflitos. Homens e mulheres precisam ser educados para uma vida sem violência, entretanto, a realidade mostra que essa cresce, nas suas mais variadas formas:

a) Violência Física

Qualquer conduta que:

- Ofenda a integridade ou a saúde corporal do indivíduo (empurrão, rasteira, mordida, tapa, soco, torção, corte, queimadura, golpes com objetos).

b) Violência Psicológica

Qualquer conduta que:

- Cause dano emocional e diminuição da autoestima do individuo;

- Prejudique ou perturbe o pleno desenvolvimento ou que vise degradar ou controlar as ações, comportamentos, crenças e decisões, mediante ameaça, constrangimento, humilhação, manipulação, isolamento, vigilância constante, perseguição contumaz, insulto, chantagem, ridicularização, exploração e limitação do direito de ir e vir do individuo;

- Cause prejuízo à saúde psicológica e à autodeterminação.

c) Violência Sexual

Qualquer conduta que:

- Constranja o individuo a presenciar, manter ou a participar de relação sexual não desejada, mediante intimidação, coação, ameaça ou uso da força;

- Induza o individuo a comercializar ou a utilizar, de qualquer modo, a sexualidade;

- Impeça o individuo de usar qualquer método contraceptivo ou que o force ao matrimônio, à gravidez, ao aborto ou à prostituição, mediante coação, chantagem, suborno ou manipulação;

- Limite ou anule o exercício de seus direitos sexuais e reprodutivos;

d) Violência Patrimonial

Qualquer conduta que configure: 
- Retenção, subtração, destruição parcial ou total de objetos, instrumentos de trabalho, documentos pessoais, bens, valores e direitos ou recursos econômicos, incluindo os destinados a satisfazer as necessidades de qualquer cidadão;

e) Violência Moral

Qualquer conduta que configure:

- Calúnia (imputar falsamente fato definido como crime),

- Difamação (imputar fato ofensivo à sua reputação);

- Injúria (ofender a dignidade ou o decoro).No ambiente escolar, todas estas formas de violência são consideradas bullying, e todos os atores que pertencem a esse lócus (professores, alunos, direção, funcionários, etc.) estão sujeitos a presenciar e/ou participar desse evento violento. Segundo Cardoso (1967, p. 40), a agressividade pode ser uma resposta, sobremaneira do discente, a várias questões que o incomodam, tais como: timidez, medo, cólera, etc; dado que o ser humano é, sobretudo um reflexo do ambiente em que passou sua infância e a este, ele deve as marcas que levará para toda a vida.

\section{A violência contra o docente e o percurso metodológico desta pesquisa}

A desvalorização da profissão docente é um dos temas mais discutidos pelos teóricos que se ocupam da educação no Brasil. Além dos baixos salários, os problemas com a qualificação profissional constituem-se numa outra forma de sucateamento dessa carreira. De acordo com Silva (1998), entre os problemas envolvidos na qualificação, a convivência de diversas modalidades de formação é fundamental para se entender a dificuldade que os profissionais de educação encontram para consolidar uma identidade profissional.

A revisão da literatura sobre a temática aqui abordada revela que a indisciplina e desinteresse dos alunos são considerados as principais dificuldades enfrentadas pelos docentes, no desempenho de suas atividades. Esses dois problemas apontados refletem uma questão complexa e de raízes profundas: o da perda da autoridade docente. $O$ professor tem dificuldades em atrair a atenção 
dos alunos para o conteúdo a ser ministrado, que parece desinteressante e longe da realidade discente. Comparada a rigidez de outrora, onde a maior parte dos alunos mantinha uma postura impecável dentro e fora da sala de aula, hodiernamente o professor encontra sérias dificuldades no que tange ao controle comportamental dos seus alunos.

Desestrutura escolar e familiar também são constantemente denotadas como importantes reflexos do panorama escolar brasileiro, onde o docente encontra-se despreparado para atender às exigências dos pais e do poder constituído, enfrentando uma sociedade com novas demandas e expectativas.

A escola particular, impelida pela expansão do capitalismo globalizante, torna-se cada vez mais uma empresa como outra qualquer, utilizando-se largamente do marketing, que segmenta e coloca o aluno na confortável condição de "cliente". O professor, por seu turno, é o empregado que se encarrega de vender um serviço e um produto ao aluno. Venda acima de tudo comprometida com um suposto sucesso discente, via aprovação e o incentivo às diferentes formas de competição (Marra, 2007).

\subsection{O percurso metodológico da pesquisa}

O presente estudo utilizou como fonte primária de informações sobre os comportamentos agressivos e anti-sociais, dados provenientes da pesquisa "Rede particular de ensino: vida de professor e violência na escola". Capitaneada pelo Sindicato dos Professores do Estado de Minas Gerais (Sinpro Minas), em parceria com o Programa de Pós-graduação em Educação e o Programa de Pós Graduação em Geografia-Tratamento da Informação Espacial da PUC Minas. De posse do banco de dados, buscou-se verificar, a percepção do docente sobre a violência nos estabelecimentos de ensino do setor privado em Minas Gerais, no ano de 2008, priorizando os atores envolvidos nas modalidades de violência continuada, observadas com maior frequência no ambiente escolar. Optou-se neste estudo, de natureza exploratória, pelo itinerário metodológico empírico de base qualitativa, utilizando a entrevista por questionário estruturado como 
instrumento para coleta de vivências, que foram interpretadas com base na análise de conteúdos, em sua dimensão qualitativa. O questionário, aplicado a 686 docentes distribuídos pelas Instituições de ensino da rede particular do estado de Minas Gerais em todas as suas modalidades, identificou idade, sexo e formação dos profissionais da educação, além das questões referentes a violência no ambiente escolar, pelos docentes percebida. Após a realização das entrevistas, tabulação, filtragem e refinamento dos dados - através do software acadêmico BULLY $\mathrm{POI}^{7}$ - as análises daí decorrentes mostraram alguns aspectos importantes para a compreensão do fenômeno da violência no ambiente da escola privada. Ressalta-se que, nessa rede, as causas da violência também são coincidentes com as causas encontradas na rede pública, excetuando-se as carências socioeconômicas e culturais.

\subsubsection{População de estudo e caracterização amostral}

A pesquisa revelou que $69 \%$ dos docentes entrevistados pertenciam ao sexo feminino, enquanto $31 \%$ compunham a ala masculina, como denota a Figura 1. Deste modo, fica evidenciado, o que historicamente caracteriza o magistério como uma profissão feminizada, tal como apontado em outras pesquisas: a associação da função materna ao magistério, a identificação da escola como extensão do lar, principalmente nas séries iniciais do ensino fundamental e a baixa remuneração.

\footnotetext{
7 Software para fins acadêmicos, concebido por Hadad \& Costa (2013), destinado ao tratamento, filtragem e refinamento dos dados que se mostraram inviáveis a consulta e mapeamento, de forma a viabilizar a geovisualização dos eventos violentos envolvendo os docentes das Instituições privadas mineiras, pleiteados nesta pesquisa. A geovisualização e posterior análise dos dados georreferenciados foi possível mediante a utilização do software QGIS e a integração deste com o PostGIS. REVISAR NUMERACIÓN NOTAS PIE DE PÁGINA????
} 
Figura 1. População amostral da pesquisa

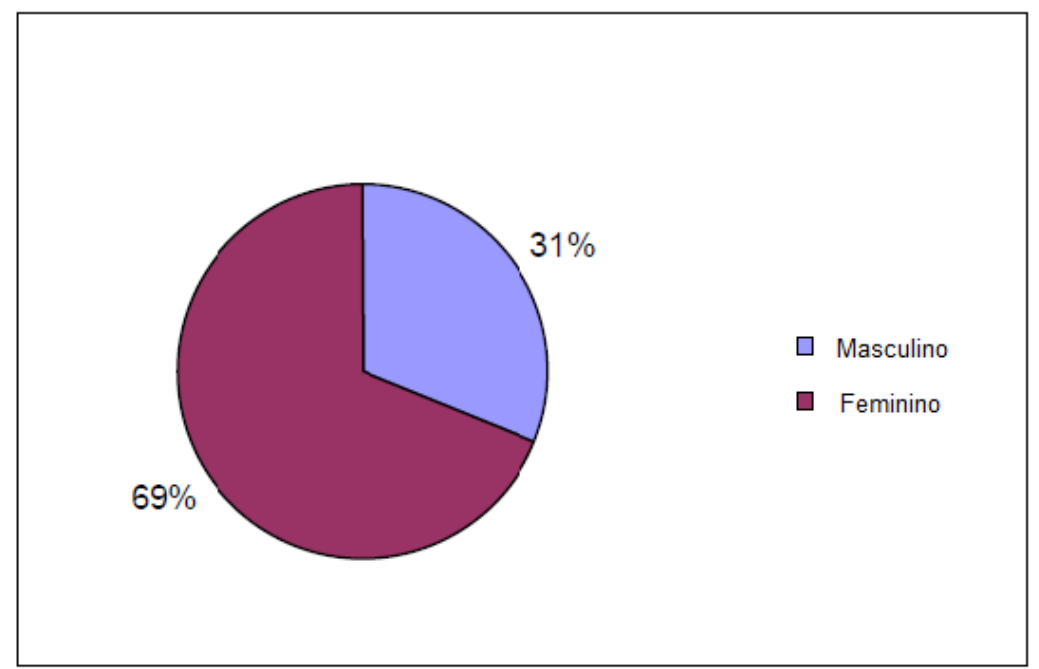

Fonte: Sinpro Minas, 2008.

Esses fatores também expressam representações sociais construídas ao longo dos processos de inserção da mulher no mercado de trabalho, em que a docência se apresentava como uma alternativa que conciliava aspectos simbólicos e materiais relativos aos papéis sociais atribuídos a ela.

$\mathrm{Na}$ Figura 2 observa-se que dos 686 professores entrevistados, $40 \%$ se encontravam na faixa entre 40 a 49 anos, evidenciando o predomínio de docentes nesta faixa de idade. A segunda maior concentração encontra-se na faixa entre 30 a 39 anos, correspondendo a $29 \%$ dos inquiridos. Professores na faixa etária entre 50 a 59 anos e 60 anos ou mais, corresponderam a $18 \%$ e $5 \%$, respectivamente do total da amostra.

Demais percentuais foram considerados desprezíveis, concluindo-se assim, que a maioria dos professores respondentes possuía idade entre 30 a 59 anos. 
Figura 2. Faixa etária da população amostral da pesquisa

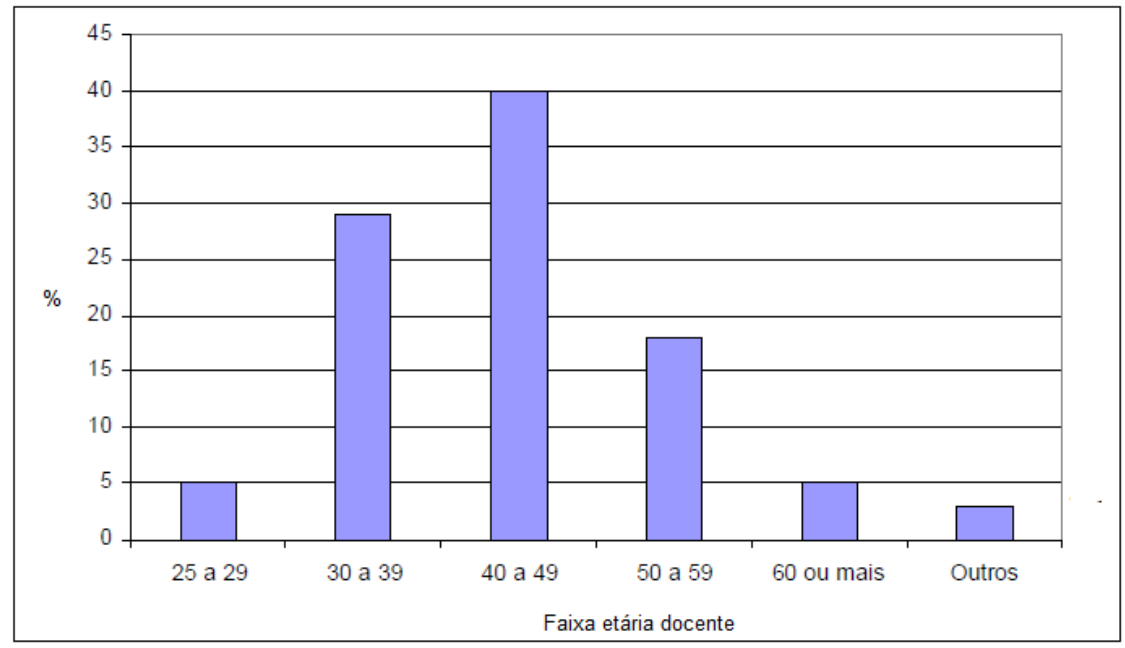

Fonte: Sinpro Minas, 2008.

$\mathrm{Na}$ Tabela 1 está explicitado o total de professores pertencentes a cada Regional contemplada neste estudo, o peso de cada uma delas em relação ao número de professores amostrados, por sexo e regional de atuação.

\section{Tabela 1 - Caracterização Amostral das Regionais Educacionais de Minas Gerais}

\begin{tabular}{|c|c|c|c|c|c|c|}
\hline \multirow[b]{2}{*}{ Regional Estadual } & \multirow[b]{2}{*}{ Cod. Região } & \multirow[b]{2}{*}{ Total de Profs } & \multirow[b]{2}{*}{ Peso } & \multicolumn{2}{|c|}{ Sexo } & \multirow[b]{2}{*}{ Amostra } \\
\hline & & & & feminino & masculino & \\
\hline BARBACENA & 1 & 1540 & 0.063 & 17 & 9 & 26 \\
\hline CATAGUASES & 2 & 530 & 0.022 & 12 & 2 & 14 \\
\hline CIDADES atendidas por $\mathrm{BH}$ & 3 & 514 & 0.021 & 14 & 4 & 18 \\
\hline CORONEL FABRICIANO & 4 & 697 & 0.029 & 13 & 8 & 21 \\
\hline DIVINÓPOLIS & 5 & 1282 & 0.053 & 23 & 8 & 31 \\
\hline GOVERNADOR VALADARES & 6 & 590 & 0.024 & 10 & 8 & 18 \\
\hline GRANDE BH & 7 & 12332 & 0.505 & 239 & 114 & 353 \\
\hline MONTES CLAROS & 8 & 1067 & 0.044 & 25 & 12 & 37 \\
\hline POÇOS DE CALDAS & 9 & 619 & 0.025 & 19 & 3 & 22 \\
\hline PONTE NOVA & 10 & 479 & 0.020 & 12 & 3 & 15 \\
\hline POUSO ALEGRE & 11 & 790 & 0.032 & 13 & 9 & 22 \\
\hline UBERABA & 12 & 1007 & 0.041 & 19 & 6 & 25 \\
\hline UBERLANDIA & 13 & 1507 & 0.062 & 31 & 18 & 49 \\
\hline VARGINHA & 14 & 1.453 & 0.060 & 25 & 10 & 35 \\
\hline Total & & 24407 & 1.00 & 472 & 214 & 686 \\
\hline
\end{tabular}

Fonte: Sindicato dos Professores do Estado de Minas Gerais (Sinpro Minas), 2008.

O cálculo amostral com correção da variância obedeceu à proporção conservadora de $50 \%$, confiabilidade de $95 \%$ e erro de precisão de $5 \%$. Com relação à margem de perdas computadas, apurou-se o total de $10 \%$. Desta tabela, 
observa-se que, computados $69 \%$ do total de docentes do sexo feminino e $31 \%$ do sexo masculino, este estudo comprovou o que outras pesquisas já apontavam: o magistério é uma profissão feminizada.

Tendo por norteador a percepção do docente, este estudo buscou levantar e identificar situações de envolvimento direto do professor em atos de violência, sobremaneira entre os pares em que estes ocorrem, buscando assim, entender as dificuldades enfrentadas pelos docentes para lecionar.

\section{Análise e discussão dos resultados}

Após a revisão da literatura, passando pelo debate acerca dos significados da violência - sobretudo a que ocorre no ambiente escolar e as percepções do docente sobre esta temática - e do percurso descrito na metodologia, apresentase, a seguir, as análises dos dados obtidos junto ao SINPRO e os seus condicionantes, identificados na bibliografia consultada. Como já citado, a presente pesquisa trabalhou com a visão de um total de 686 docentes sindicalizados, distribuídos nas 14 Regionais Educacionais do Estado de Minas Gerais. Ressalta-se que durante a aplicação dos questionários, não se percebeu resistência nem, tampouco, má vontade dos docentes em participarem das entrevistas. Fez-se opção pelo questionário escrito com perguntas objetivas e subjetivas, de forma que os entrevistados ficassem mais à vontade em responder as mesmas, com sinceridade e sigilo.

\subsection{Localização das Regionais Educacionais e Docentes Sindicalizados}

A figura 3 mostra a configuração do atendimento do SINPRO pelo Estado de Minas Gerais no ano de 2008. 
Figura 3. Mapa de localização dos municípios atendidos pelo SINPRO, subdividido em regionais

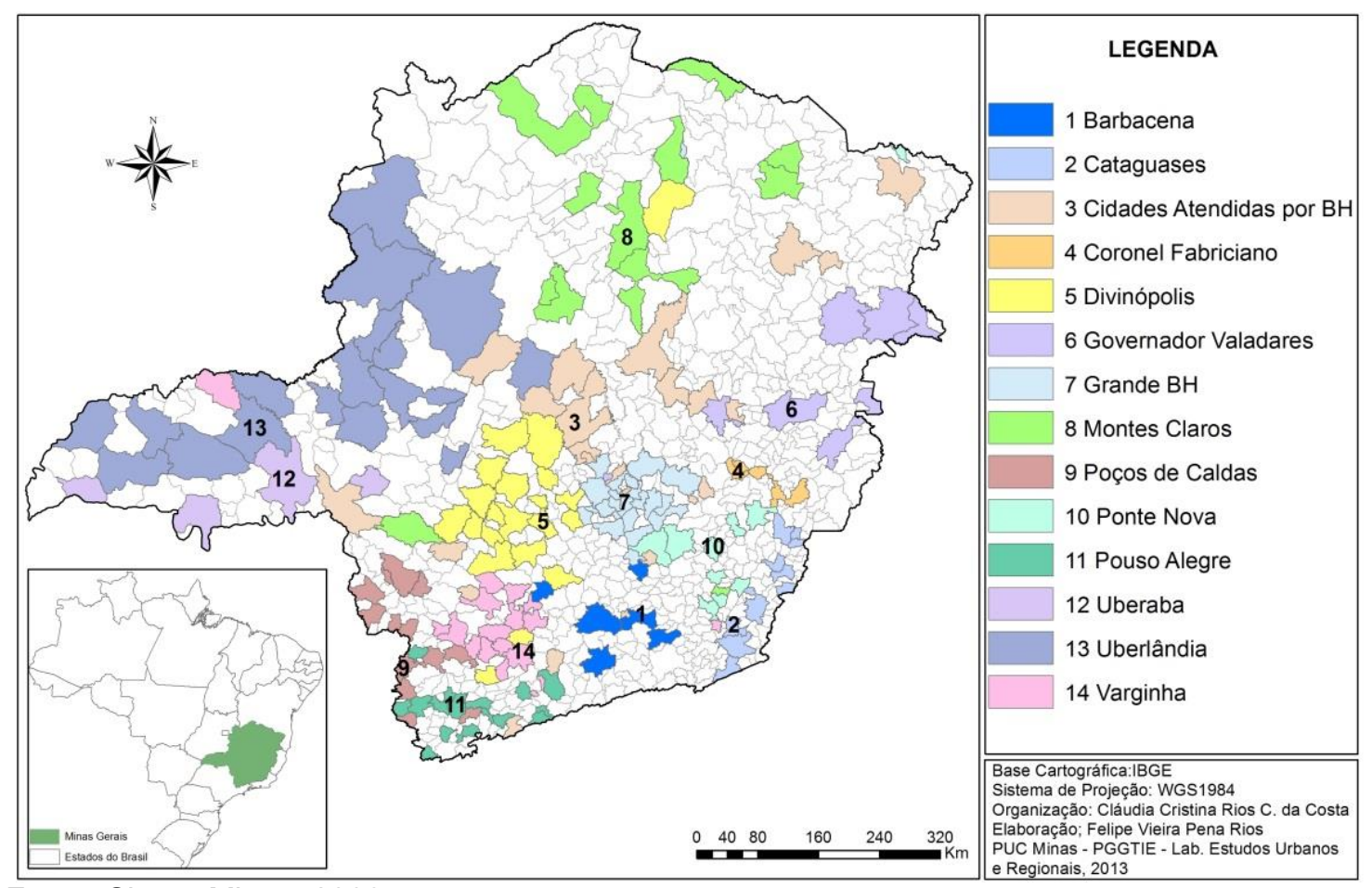

Fonte: Sinpro Minas, 2008.

Observa-se que as 14 regionais não são contíguas e muitos dos 853 municípios não contavam a época, com a presença do sindicato. A título de exemplo, os municípios que compõem a região do Vale do Jequitinhonha não possuíam relações de pertencimento a uma regional específica. Os docentes sindicalizados deste lócus, são atendidos pela regional denominada de Grande $\mathrm{BH}$.

Do total de docentes questionados, $37 \%$ disseram exercer a docência no ensino superior, enquanto, 56\% estavam alocados na educação básica. Desse percentual, a maior concentração de professores se encontrava nas séries iniciais do ensino fundamental, correspondendo a $20 \%$, seguidos pelos $14 \%$ concentrados nas séries finais. O percentual dos professores que lecionavam no ensino médio foi de $11 \%$. Do contingente docente entrevistado, 25\% ministravam aulas na rede particular de ensino, entre 16 a 20 horas semanais. Dos docentes entrevistados, $75 \%$ (23\% homens e $52 \%$ mulheres) concordaram que uma das principais causas 
da violência no ambiente escolar é a omissão familiar. Tal percepção atesta os estudos sobre a escola, que historicamente, se manteve hermética à participação da família e de outros atores da comunidade escolar perante as suas funções.

Hodiernamente, estudos apontam que a solução mais plausível para o enfrentamento dos conflitos na escola, implica em sua abertura e comunhão com o seu entorno, bem como os órgãos públicos que gerenciam a educação nas esferas federais, estaduais e municipais.

4.2. A percepção da violência no ambiente escolar: os atores envolvidos

Questionados se estavam despreparados para lidar com os eventos de natureza violenta na escola, $67 \%$ dos docentes concordaram e os que concordaram em parte somaram $26 \%$. Evidenciou-se, assim, a lacuna deixada na formação docente, bem como as políticas públicas de formação continuada na preparação destes para o enfrentamento dos problemas sociais da contemporaneidade, que acabam por atingir também a escola, particularmente no tocante à violência.

Mediante os objetivos propostos neste estudo, foram apresentadas aos docentes, situações consideradas violentas no ambiente escolar (Vide Figura 4). Questionados se haviam presenciado tais eventos, foram oferecidas opções, para que os professores formassem os pares de atores envolvidos nestes episódios, tais como: professor, aluno, direção, comunidade, família, outros, escola, outros profissionais da escola.

A partir destes dados, foram selecionados os pares mais frequentes, em cada situação na qual esteve envolvida a pessoa do professor. Dentre estes pares foram considerados aqueles que alcançaram um percentual de respostas a partir de $5 \%$, inclusive. 
Figura 4. Pares mais citados com o envolvimento do professor em cada situação

\begin{tabular}{|c|c|c|c|c|}
\hline Situação de Violência & $1^{\circ}$ Par mais citado & $\%$ & $2^{\circ}$ Par mais citado & $\%$ \\
\hline Assédio moral & Professor - aluno & 30 & Professor-direção & 25 \\
\hline \multirow[t]{2}{*}{ Assédio sexual } & \multirow[t]{2}{*}{ Professor - aluno } & \multirow[t]{2}{*}{54} & $\begin{array}{l}\text { Professor-outros } \\
\text { Profissionais da } \\
\text { escola }\end{array}$ & 5 \\
\hline & & & Professor-direção & 5 \\
\hline Chantagem & Professor - aluno & 37 & Professor-direcão & 17 \\
\hline Roubo & Professor - aluno & 7 & - & - \\
\hline Furto & Professor - aluno & 10 & - & - \\
\hline Sequestro & Professor - outros & 16 & - & - \\
\hline Lesão física ou psicológica & Professor - aluno & 21 & Professor-direção & 14 \\
\hline Agressão física & Professor - aluno & 18 & - & - \\
\hline Agressão verbal & Professor - aluno & 38 & Professor-professor & 5 \\
\hline Ameaça & Professor - aluno & 45 & Professor-direção & 15 \\
\hline Intimidação & Professor - aluno & 37 & Professor-direção & 18 \\
\hline \multirow[b]{2}{*}{ Porte de armas } & Professor - aluno & 6 & - & - \\
\hline & Professor - outro & 6 & - & - \\
\hline Uso de drogas & Professor - aluno & 7 & Professor-professor & 4 \\
\hline Dano ao patrimônio pessoal & Professor - aluno & 36 & - & - \\
\hline Indisciplina & Professor - aluno & 54 & - & - \\
\hline Apelido ou gozação & Professor - aluno & 16 & - & - \\
\hline Descumprimento das leis trabalhistas & Professor - escola & 49 & Professor-direção & 37 \\
\hline Desrespeito a autonomia do professor & Professor - aluno & 55 & Professor-direção & 20 \\
\hline Sobrecarga de trabalho & Professor - escola & 41 & Professor-direção & 36 \\
\hline Discriminação de gênero & Professor - aluno & 47 & Professor-professor & 11 \\
\hline Discriminação por idade & Professor - aluno & 30 & Professor-direção & 24 \\
\hline Discriminação por opção sexual & Professor - aluno & 22 & - & - \\
\hline Discriminação socioeconômica & Professor - aluno & 17 & Professor-professor & 7 \\
\hline Discriminação por deficiência física & Professor - aluno & 14 & - & - \\
\hline Discriminação religiosa & Professor - aluno & 22 & Professor-professor & 5 \\
\hline Discriminação de cor & Professor - aluno & 23 & - & - \\
\hline
\end{tabular}

Fonte: Sinpro Minas, 2008.

Observa-se que dentre os eventos considerados violentos, os mais citados envolveram os pares "professor-aluno" e "professor-escola". Considerando, sobremaneira, o primeiro par mais citado para cada situação violenta, destacaram-se: Desrespeito à autonomia do professor (55\%), assédio sexual e ameaça (54\%), discriminação de gênero (47\%) e intimidação (45\%), envolvendo o par "professor-aluno", ao passo que o descumprimento das leis trabalhistas (49\%) e a sobrecarga de trabalho (41\%), despontaram como eventos considerados violentos, envolvendo o par "professor-escola". 
Não obstante a maioria dos professores ter negado a existência da violência na escola em que trabalham, há um percentual de docentes que admitiram ter presenciado fatos de violência em determinados turnos e horários escolares. Tais análises, em combinação, sugerem a existência de violência na rede particular de ensino.

\subsection{A percepção da violência no ambiente escolar:}

Natureza das situações apresentadas aos entrevistadosAos docentes entrevistados foram apresentadas algumas categorias que pudessem pormenorizar a natureza das situações de violência, por eles presenciadas no ambiente escolar:

- Categorias ligadas às incivilidades, em que se inclui a indisciplina e apelido/gozação de aspecto pejorativo.

- Categorias ligadas a danos e a possibilidade de danos físicos e psicológicos graves, em que se inclui lesão física e psicológica grave, homicídio, agressão física, agressão verbal, ameaça, intimidação, porte de armas e tiroteio.

- Categorias ligadas aos direitos inerentes ao cargo/função docente, em que se inclui desrespeito à autonomia do professor no exercício da docência, descumprimento dos direitos trabalhistas e sobrecarga de trabalho.

A indisciplina foi considerada violência pela maioria dos professores entrevistados, como denota a Figura 5. Destes, 98\% declararam ter presenciado esse tipo de situação na escola (destaque para os percentuais de docentes alocados nos municípios de Belo Horizonte, Betim, Contagem, Cataguases, Coronel Fabriciano, Pouso Alegre, e Sete Lagoas). O apelido ou gozação, de aspecto pejorativo, foi considerado violência por $91 \%$ dos professores e $86 \%$ deles presenciou esse tipo de situação. Esses percentuais confirmam a polissemia de conceito de violência, que tem se confundido com o conceito de indisciplina e outras incivilidades. 
Figura 5. Categorias ligadas às incivilidades

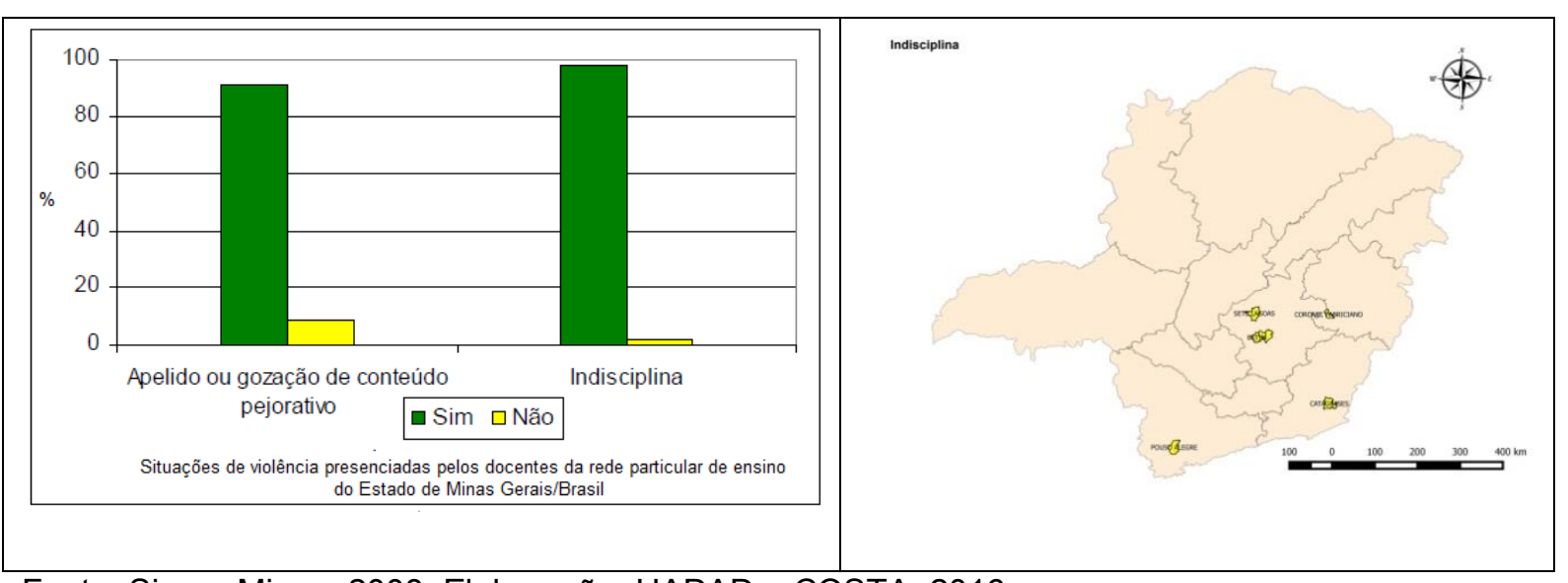

Fonte: Sinpro Minas, 2008. Elaboração: HADAD e COSTA, 2016

Dos professores respondentes, $100 \%$ consideraram as situações evidenciadas na Figura 6 como violência, exceto a intimidação que obteve o percentual de $98 \%$ dos professores. Quanto a ter presenciado esses fatos na escola, mais da metade dos professores, $62 \%$, disseram ter presenciado a agressão verbal (maiores percentuais observados nos municípios de Betim, Ituiutaba, Montes Claros, Passa Quatro, Pouso Alegre, Sete Lagoas e Varginha).

Figura 6. Categorias ligadas a danos e a possibilidade de danos físicos e psicológicos graves

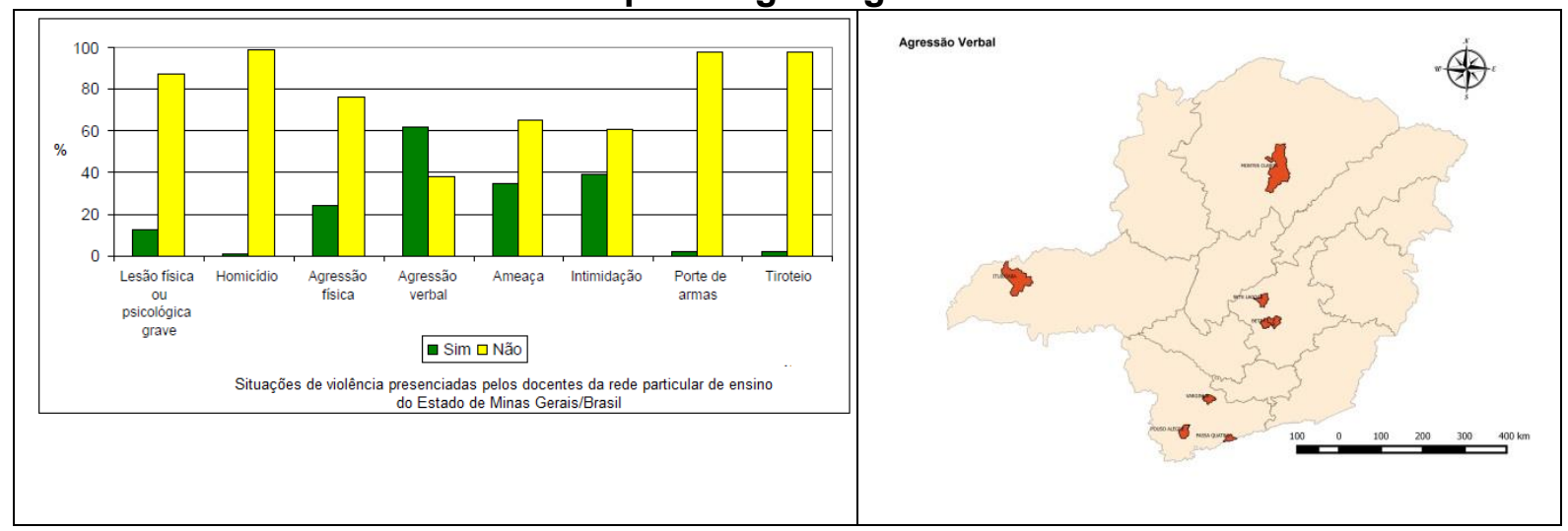

Fonte: Sinpro Minas, 2008. Elaboração: Hadad e Costa, 2016 
O segundo maior percentual se equilibra nas situações de ameaça e de intimidação, respectivamente, com 35\% e 39\%. Em menor monta, $24 \%$ congrega os que disseram ter presenciado agressão física e 13\%, lesão física ou psicológica grave. Os percentuais referentes às demais situações são desprezíveis.

$\mathrm{Na}$ categoria ligada aos direitos inerentes ao cargo/função docente, 91/\% dos professores consideraram como violência o desrespeito à sua autonomia no exercício da docência, e $89 \%$ consideraram como violência o descumprimento dos direitos trabalhistas. Um percentual um pouco menor, $81 \%$, considerou como violência a sobrecarga de trabalho (Figura 7).

Figura 7. Categorias ligadas aos direitos inerentes ao cargo/função docente

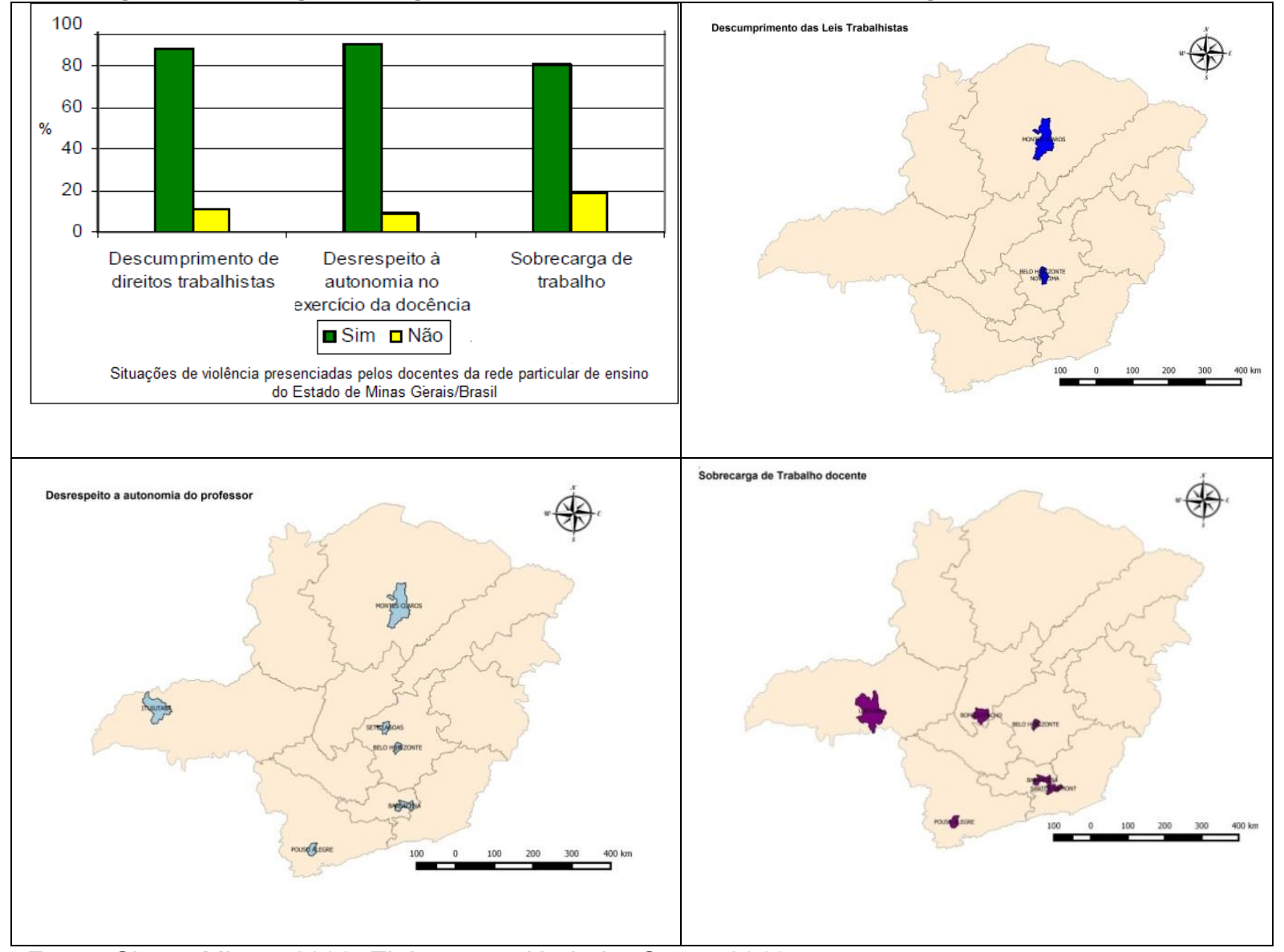

Fonte: Sinpro Minas, 2008. Elaboração: Hadad e Costa, 2016 
Quanto a essas situações na escola, o percentual dos que disseram ter presenciado desrespeito à autonomia do professor no exercício da docência (destaque para os percentuais dos municípios de Belo Horizonte, Sete Lagoas, Montes Claros, Barbacena, Pouso Alegre e Ituiutaba) foi de $52 \%$, seguidos pelos $41 \%$ (enfatizando os percentuais de docentes alocados nos municípios de Belo Horizonte, Barbacena, Bom Despacho, Pouso Alegre, Santos Dumont e Uberaba) que disseram ter presenciado sobrecarga de trabalho e dos $38 \%$ dos professores que declararam ter presenciado o descumprimento das leis trabalhistas (destaque para os percentuais de docentes alocados nos municípios de Belo Horizonte, Nova Lima e Montes Claros).

Tais dados sugerem que, de fato, na rede particular de ensino não são incomuns atos que transgridem as leis trabalhistas e inibem a autonomia do trabalho docente, como por exemplo, a redução de carga horária e a demissão de professores, sem justa causa, ou por motivos alheios à atividade docente. Também não é fato incomum a existência de medidas "pedagógicas" justificadas pelo discurso da reorganização do trabalho na escola e que, muitas vezes, incidem diretamente na atividade e autonomia que o professor deve ter em sala de aula. Vale ressaltar que as relações de aprendizagem são norteadas por processos que envolvem professores e alunos, cuja dimensão de subjetividade e especificidade foge ao controle de mensurações utilizadas para assegurar outras funções, a exemplo daquelas exercidas na indústria.

\section{Considerações Finais}

Na rede particular de ensino, as causas de violência são coincidentes com aquelas encontradas na rede pública, excetuando-se as carências socioeconômicas, desfazendo-se o mito de que a pobreza induz à violência. Esta pesquisa constatou a incipiência de estudos sobre a violência no setor privado de ensino, sobremaneira àquela imposta aos docentes. Isso se deve, em parte, pela dificuldade de acesso às informações, que nem sempre são disponibilizadas pelas escolas, como forma de preservarem sua imagem no "competitivo mercado" 
educacional. É importante destacar que dentre as situações confirmadas como sendo de violência, tais como as agressões verbais, as gozações e intimidações ou mesmo a indisciplina têm sido problematizadas em outras investigações como sendo violentas, uma vez que, em muitas delas, essas situações são consideradas como incivilidades, ou seja, fatos sem maior gravidade. De forma generalizada, os docentes disseram não ter presenciado esses tipos de violência na sua escola. As exceções ficaram por conta da agressão verbal, as lesões aos direitos e à autonomia docente, os apelidos e gozações - estas últimas correspondentes ao que se denomina bullying em inúmeras pesquisas. Corroborando com outros estudos, a indisciplina, nesse estudo, foi considerada como violência. Em que pese a maioria dos professores ter declarado que não presenciou situações de violência na escola, os dados a seguir permitiram afirmar o contrário:

1. Em relação aos sujeitos envolvidos nas situações de violência ocorridas nas escolas, a expressiva maioria das respostas obtidas, refere-se ao par professoraluno;

2. Os professores confirmaram a ocorrência de situações de violência em diferentes turnos e em diferentes horários escolares.

Tais indicadores permitem afirmar a existência de violência nas escolas da rede de ensino particular e o envolvimento do professor nas situações de violência. Confirma-se também que a sala de aula continua sendo o foco de tensão entre professor e aluno. Neste sentido, faz-se mister destacar que as opiniões dos professores permitiram um diálogo com as categorias de violência apresentadas por diversos estudiosos da temática, que referenciaram a análise dos resultados desta pesquisa.

Este estudo também apontou que os docentes concordaram que, as causas da violência na escola estão relacionadas: à omissão familiar; ao tráfico e uso de drogas; à falta de diálogo entre a escola e seu entorno; ao tratamento prepotente dispensado pelos alunos aos diversos profissionais da escola; à indiferença dos funcionários para com eles - alunos e professores; à região violenta em que a 
escola se localiza, bem como à criminalidade existente nas suas imediações e ao estímulo dos meios de comunicação às atitudes violentas.

\section{Referências Bibliográficas}

Abramovay, M. (Coord.). (2006). Cotidiano das escolas: entre violências. Brasília: UNESCO.

Abramovay, M., \& Ruas, M. G. (2004). Violência nas escolas. Brasília: UNESCO. Instituto Ayrton Sena. UNAIDS. Banco Mundial. USAID. Fundação Ford. CONSED. UNDIME.

Blaya, C. (2002). Clima escolar e violência nos sistemas de ensino secundário da França e da Inglaterra. In: DEBARBIEUX, E. e BLAYA, C.(orgs). Violência nas escolas e políticas públicas. Brasília: Unesco.

Camacho, L.M.Y. (2001). A violência nas práticas escolares de adolescentes. ANPED, GT Sociologia da Educação. CD-ROM.

Candau, V. M. (Org.) (2002). Reinventar a escola. 3. ed. Petrópolis: Vozes.

Cardoso, O. B. (1967). Problemas na Infância. 5. ed. São Paulo: Edições Melhoramentos, 211p.

Charlot, B. (2002). A violência na escola: como os sociólogos franceses abordam essa questão. Revista Sociologias, Porto Alegre, n.8, ano 4, 432-443, jul./dez.

Constantini, A. (2004). Bullying, como combatê-lo?: Prevenir e enfrentar a violência entre jovens. São Paulo: Itália Nova.

Cruz, G. V. S. F., \& Pereira, W. R. (2013). Diferentes configurações da violência nas relações pedagógicas entre docentes e discentes do ensino superior. Revista Brasileira de Enfermagem (Impresso), v. 66, 241-250.

Espinheira, G. (Coord.). (2004). Sociabilidade e violência: criminalidade no cotidiano de vida dos moradores do Subúrbio Ferroviário de Salvador. Salvador: EDUFBA/ Ministério Público do Estado da Bahia, 124-139.

Fante, C. (2005). Fenômeno Bullying: como prevenir a violência nas escolas e educar para a paz. 2 ed. São Paulo: Verus.

Fromm, E. (1982). Anatomia da destrutividade humana. $2^{\mathrm{a} e d . ~ S a ̃ o ~ P a u l o: ~}$ Guanabara.

Hadad, R. M., \& Costa, C. C. R. C. (2013). Bully POI. Laboratório de Estudos Urbanos e Regionais do Programa de Pós Graduação em Geografia - Tratamento da Informação Espacial: Pontifícia Universidade Católica de Minas Gerais.

Hanke, P.J. (1996). Putting school crime into perspective: self-reported school victimizations of high school seniors. Journal of Criminal Justice. 
Jacometti, M., Blasius, L., Polido, M. J., \& Andrade, M. M. (2014). Até que ponto o bullying influencia o aumento da demanda por Educação de Jovens e Adultos?. ETD. Educação Temática Digital, v. 16, p. 118-137, 2014.

Lopes Neto, A. A., \& Saavedra, L. H. (2003). Diga não para o Bullying! Rio de Janeiro: Publicação financiada pela Petrobrás.

Marra, C. A. S. (2007). Violência escolar: a percepção dos atores e a repercussão no cotidiano da escola. São Paulo: Annablume.

Olweus, D. (1993). Bullying at school: What we know and what we can do. London, Lackwell, $140 \mathrm{p}$.

Ortega, R. P. (2001). "Project Sevilla contre La violence scolaire: Um modèle d'intervention éducative à caractere ècologique". In: DEBARBIEUX, E. e BLAYA, C. (dir). La violence em millieu scolaire-3- dix approaches em Europe. Paris: Ed. ESP, 91-112.

Platão (1990). A República. Livro IX. Lisboa: Fundação Calouste Gulbenkian.

Silva, W. C. (Org.). (1998). Formação dos profissionais da educação. Niterói: EdUFF. Capítulos 3, 5 e 6.

Sposito, M. P. (2001). Um breve balanço da pesquisa sobre violência escolar no Brasil. Revista Educação e Pesquisa, São Paulo, v. 27, n.1, 87-103, jan./jun. Tosta, S. F. P., Rigotti, J. I. R., Marra, C. A. S., \& Dantas, D. C. (2009). O que pensa o professor da rede particular de ensino de MG sobre a violência em meio escolar, 2009. São Carlos. Anais... IX Encontro em Pesquisa em Educação da Região Sudeste. São Carlos : UFScar.

Zaluar, A., \& Leal M.C. (2001). Violência extra e intramuros. Revista Brasileira de Ciências Sociais, v. 16, n. 45.

\section{Para citar este artículo:}

Rios Caxias, C., Alves, A., Moreira, R. y Pereira, S. (2016). Situações De Violência Envolvendo $O$ Docente Nas Escolas Particulares Mineiras: Análise Exploratória Sobre Um Tema Recorrente. Collectivus, Revista de Ciencias Sociales, 3(2), 156-181. doi: http://dx.doi.org/10.15648/Coll.2.2016.8 